\title{
Peertechz
}

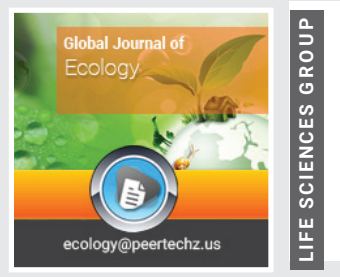

Review Article

\section{Climate Change Challenge}

$26^{\text {th }}$ Conference of Parties

(COP26) climate summit

is crucial but may be disappointing?

\section{K Suresh*}

MD, DIH, DF, FIAP, FIPHA, FISCD, Public Health Consultant \& Visiting Professor School of Environmental Science, Public Health and Sanitation Management, Karnataka State Rural Development and Panchayat Raj University (KSRDPRU), GADAG, Karnataka, Pin-582101, India

Received: 01 November, 2021

Accepted: 08 November, 2021

Published: 09 November, 2021

*Corresponding author: Dr. Suresh Kishanrao, MD, DIH, DF, FIAP, FIPHA, FISCD, Public Health Consultant \& Visiting Professor School of Environmental Science, Public Health and Sanitation Management, Karnataka State Rural Development and Panchayat Raj University (KSRDPRU), GADAG, Karnataka, Pin-582101, India, Tel: 918029571102, 919810631222;

Email:ksuresh.20@gmail.com

Keywords: Climate chane; COP; Climate change and Health implications; Universal Health Coverage (UHC) Outbreaks; Pandemics disrupting UHC

Copyright License: (c) 2021 Suresh K. This is an open-access article distributed under the terms of the Creative Commons Attribution License, which permits unrestricted use, distribution, and reproduction in any medium, provided the original author and source are credited.

https://www.peertechzpublications.com

\section{Abstract}

Human activity is the main cause of climate change. People burn fossil fuels and convert land from forests to agriculture. Burning fossil fuels produces carbon dioxide, a greenhouse gas. Climate change due to vehicular movements, industries, and deforestation for creating newer inhabitations affects the environmental and social determinants of health. An effective public health response to climate change is involves preventing injuries and illnesses, escalating public health preparedness, and reducing risk of consequences of all listed climate change immediate support, manage health effects and outbreaks.

The world leaders are gathering in Glasgow for COP26, today the October 31st, 2021, to carry forwards the unfinished agenda. The process is ruled by arriving at consensus, and the pace is set by the least willing countries. In 2019, developed countries provided \$16.7 billion as a grant, that amounts to just \$1 per month for climate finance. Developed countries can surely afford more than this. A credible climate finance plan from them is, therefore, crucial. The world's 20 biggest economies recently endorsed a landmark deal on a global minimum corporate tax rate of $15 \%$ and will aim to implement the rules by 2023 for climate financing.

The main reason why cop26 process matters is that the science, diplomacy, activism, and public opinion that support it make up the best mechanism the world currently must help it come to terms with a fundamental truth. Looking at the progress made since the imitation of COP so far and minimal groundwork that has been done to achieve them, most of the demands may not be met.

India's ambitious 450 GW renewable energy goal by 2030, its hydrogen mission, plan to move Indian railways to 'net-zero' emission by 2030 , land degradation neutrality and massive programme to increase forest cover- natural carbon sink the key points the country will commit to drive home.

Forty-five nations pledged to step up protection of nature and overhaul farming to cut greenhouse gas emissions, but major economies led by the US, Japan and Germany and developing nations such as India, Indonesia, Morocco, Vietnam, Philippines, Gabon, Ethiopia, Ghana, and Uruguay backed from commitments. The steps include leveraging over $\$ 4$ billion of new public sector investment into agricultural innovation, including the development of climate-resilient crops and regenerative solutions to improve soil health.

I think climate challenges will be met, not because of summits and global idealism but because of enormous sums likely to be spent on green innovation by profitdriven corporations, incentivised by modest government subsidies and mandates

Material \& methods: This article is a review of available literature on Impact of climate change on health and global Climate change efforts, in press and various government and UN agency documents. 


\section{Introduction}

The world leaders are gathering in Glasgow for COP26, today the October 31st, 2021. The process is ruled by arriving at consensus, and the pace is set by the least willing countries. In the similar meetings of Kyoto in 1997, Copenhagen in 2009 and Paris in 2015 - a deafening verbal commitment was made, but the outcome is not visible. in Paris in 2015, countries had pledged to keep the rise in Earth's temperature well below $2^{\circ} \mathrm{C}$. The UK is pushing for a treaty to "consign coal power to history", the US wants a net-zero deal, the Association of Small Island States (AOSIS) has demanded for keep the rise in Earth's temperature well below $1.5^{\circ} \mathrm{C}$ declaration. Least Developing Countries (LDCs) want climate polluters to pay them billions of dollars for loss and damage, and Like-Minded Developing Countries (LMDCs) want $\$ 100$ billion climate finance and carbon space. The world's 20 biggest economies (G20) on $30^{\text {th }}$ October 21 endorsed a landmark deal on a global minimum corporate tax rate of $15 \%$ and will aim to implement the rules by 2023 for climate financing.

Climate change due to vehicular movements, industries, and deforestation for creating newer inhabitations affects the environmental and social determinants of health. The affects are becoming explicitly life threatening in urban areas and deforestation of forests. Clean air, safe drinking water, unadulterated food and insecure shelters are becoming beyond the reach of poor and lower middle-class population in most of the Indian cities. Municipal corporations are finding it unamenable to provide the basic amenities. Infections like diarrhoeal diseases, vector borne diseases like Malaria, Dengue, respiratory illnesses like Asthma, pneumoconiosis, Bronchitis, Chronic Pulmonary Obstructive Diseases (COPD) and Bronchial Asthma, even some of the cancers pose higher risk with deteriorating climate. Reducing emissions of greenhouse gases through better transport, food and energy can result in health protection and promotion. The Governments need to develop techniques and policies to prevent any pollution or harm to native plants, animals and humans who live there while building highways, factories, or mining operations close to human habitats. Clamping down on planned obsolescence, through the process of designing products to be deliberately not long-lasting. The governments have started a drive to plant mangrove trees to preserve the forest, but they also need to try to understand the diversity of crops or the need for ecofriendly sustainable ways to protect embankments. The science and technology must be put to use to ensure development without the destruction of one's way of life as we observe that many people have been displaced from their homes and islands because of rising water levels. All actions are not necessarily the Government responsibility.

Every responsible individual and small communities must Learn more about our carbon emissions, commute by carpooling or using mass transit, Plan and combine trips, drive more efficiently and Switch to electricity generated by energy sources with low-or no-routine emissions of carbon dioxide. All can influence creating better awareness among poor and illiterate, that helps them connect the dots between climate change and their everyday lives be it extreme weather, health, food, water, livelihood, and moral values and facilitating actions of lifestyles leading to saving, water, household gardening, and recycling waste. The community including Residents' Welfare Associations (RWA), Panchayats, Municipal authorities, NGOs, and CBOs must work towards building backyard forests and increasing green cover through vertical gardens, adopting parks for maintenance, desegregation of the household waste etc.

Countries of the world that assemble must come to terms with a fundamental truth as the dream of a planet of almost 8bn people living in material comfort will be unachievable if it is based on an economy powered by coal, oil, and natural gas. In the long run, the only way to keep growing is by leaving fossil fuels behind. That requires Asian countries, to forgo much more by way of future emissions than the countries of the developed world, where emissions are already declining.

While developed countries depend on gas for electricity, coal provides $70 \%$ of India's and $62 \%$ of China's electricity production. While phasing out of coal power is essential to combat the climate crisis, so is gas power. Countries are not convinced that prioritising one over the other is the right way to move ahead. As a large population depends on coal for livelihood in developing countries like India, huge investments are required to transition coal regions to non-coal economies. There has not been any discussion on how this coal transition will happen and who will pay for the closure of coal mines and power plants and without discussing the nitty-gritty, a coal power treaty is unrealistic.

Unfortunately, most of these demands will not be met because the groundwork has not been done to achieve them For example, the case of coal power phaseout, the UK is pushing to end coal power by 2030 in developed countries and by 2040 in the rest of the world. But it has failed to get support from most coal consuming countries including the top two consumers namely India and China. It is also worth reminding our people that next few generations will have to bear the daunting cost of limiting emissions in developing countries. Developed countries can put out a new plan for climate finance that is ambitious and credible. In 2019, developed countries provided \$16.7 billion as a grant, that amounts to just \$1 per month for climate finance. Developed countries can surely afford more than this. A credible climate finance plan from them is, therefore, crucial.

\section{Climate change \& health implications}

Global warming poses public health risks due to declining air quality, rising temperatures, increased frequency of extreme weather events, and higher incidences of food- and water-borne pathogens and allergens resulting increased morbidity and mortality. Climate change is the biggest threat to the global population. The health professionals face many challenges and are already responding to the health harms caused by this crisis, but that would not serve the purpose unless Intergovernmental Panel on Climate Change (IPCC) 
mobilizes all countries based on their economic supportive potential to pitch in to avert the health impacts and prevent millions of climate change related deaths, morbidity and most importantly post-natural calamities (Floods, draughts and earth quakes) outbreaks of infectious diseases like Cholera, Vector borne diseases breaks and disruption in health services leading to deaths, malnutrition and long term disabilities apart from losses of houses and social infrastructure of development.

Global heating of $1.5^{\circ}$ Celsius is not considered safe, and every additional $0.1^{\circ} \mathrm{C}$ temperature warming will pose serious health problem. Unfortunately, the people who get affected by such change are not those who contribute for climate crisis but are those living in low-income or disadvantaged countries and communities. In the background of Paris agreement that had pledged to keep the rise in Earth's temperature well below $2^{\circ} \mathrm{C}$ by 2030 may have to be redefined. Climate change will seriously jeopardise the global commitments of achieving Universal Health Coverage (UHC) by 2030 in various ways. We have been seeing how the Covid 19 Pandemic has disrupted the health services and efforts marching towards UHC since April 2020. It would increase the disease burden and exacerbate the barriers to access available health services due to increase in health care spends with many being not insured.

1) The climate sensitive health risks may differ from region to region but by and large include air pollution and its consequences - Asthma \& Cardiovascular diseases

2) Allergen and Pollens: Respiratory \& Skin allergies, Asthma

3) Vector borne diseases- Malaria, Dengue, Viral encephalitis syndromes, Chikungunya etc.

4) Waterborne diseases- Cholera, Typhoid, Leptospirosis, Campylobacteria infections, etc.

5) Food Security \& water supply related conditions: Malnutrition and diarrheal diseases

6) Environmental Degradation: Forced migration, civil conflicts, and mental health challenges

7) Mental Health \& Stress related disorders- loss of livelihood, poor wages, and Indirect effects of anxiety and depression and the consequences of mass migration and regional conflicts.

8) Heavy Precipitation- leading to Floods and their immediate consequences like drowning of human and animals, water intrusion in the houses and other buildings, mould contamination affecting indoor air quality, dampness related increase in Asthma, pneumonia \& outbreaks

9) Extreme Temperatures- Prickly heat, heat stroke, heat waves leading to Cardiovascular failures and deaths

10) Droughts: Will lead to wildfires, dust storms degrading air quality leading to fungal infections extreme heat episodes and reduced water quantity and quality
11) Wildfires- Wildfire smokes contain particulate matter, Carbon monoxide, nitrogen oxides and other organic pollutants, that make air quality poor leading to increased respiratory infections.

Children across the world are at a higher risk as over $90 \%$ of children are exposed to air pollution, over $30 \%$ of children each are exposed to a) heatwaves, b) water scarcity- increasing water stress, droughts, and competition for water, that will increase as the world temperature rises. One in 4 children is exposed to Vector borne diseases as the climate change is turning suitable for pathogens and vectors survival like mosquitoes. Similarly, 1in 6 children is exposed to Cyclones, 1 in 7 to floods \& $1 / 10$ to coastal flooding disasters [1].

An effective public health response to climate change involves preventing injuries and illnesses, escalating public health preparedness, and reducing risk of consequences of all listed climate change immediate support, manage health effects and outbreaks. public health effects of climate change can be addressed through five Steps of 1) Anticipate Climate Impacts and Assessing Vulnerabilities. 2) Project the Disease Burden and be prepared to take anticipatory actions 3) Assess Public Health Interventions that may be required and plan for the execution of the same at the shortest interval. 4)Develop and Implement a Climate and Health Adaptation Plan and 5) Evaluate Impact and Improve Quality of Activities and services for the future. Addressing water quality, food control, waste managements, health surveillance of premises, surveillance and prevention of communicable diseases, vector control and environmental pollution control can mitigate majority of the climate change crisis.

The main reason why cop 26 process matters is that the science, diplomacy, activism, and public opinion that support it make up the best mechanism the world currently must help it come to terms with a fundamental truth. Moreover, the fact that in a recent UNDP opinion poll, whooping $65 \%$ of adults and more than $70 \%$ of Teenagers under 18 years out of nearly 700,000 participated people of G 20 countries except China, who think Climate Change is a Global Emergency [2]. The issue matters most to about 1.5bn Asians living in the tropics and Hundreds of millions of them live near the coasts. For their economies to continue to grow, they will need ever more energy. If this comes in the fossil-fuelled manner of past decades they will have to bear the mounting costs of adapting to and living with floods, storms, heatwaves, and droughts long before they get rich. As the world heats up, they will have to run faster just to stay in the same place. Zero-emissions technology could free them from this dismal bind; therefore, they must tap into a supply of development-promoting Solar energy that is, unlimited and almost free.

Of course, getting to net-zero emissions is not going to be easy and will come with many challenges, including timely decarbonisation of heavy industries like cement and aluminium, dealing with agriculture sector that requires political sensitivity, and helping with a just and equitable transition of energy sector while ensuring that those that are disproportionately impacted are protected from climate impacts. Protecting those employed in traditional energy sectors of coal, oil and gas will also be crucial. This is where 
global cooperation will be most necessary, not just in providing finance for India to undertake the transition but to learn from each other on how these new challenges should be dealt with, and how the transition can be undertaken whilst minimising socio-economic impact.

\section{What does public health expect from COP26?}

The WHO's COP26 Special Report on Climate Change and Health, released on $11^{\text {th }}$ October 2021 [3]. It expects all countries to commit to decisive action at COP26 to limit global warming to $1.5^{\circ} \mathrm{C}$ in our own interests to make human health and equity central to all climate change mitigation and adaptation actions. The report quotes increasingly frequent extreme weather events, such as heatwaves, storms, and floods, that kill thousands and disrupt millions of lives, while threatening healthcare systems and facilities when they are needed most. Changes in weather and climate are threatening food security and driving up food-, water- and vector-borne diseases, such as malaria, while climate impacts are also negatively affecting mental health. Air pollution, because of burning fossil fuels, a driving force of climate change, causes 13 deaths per minute worldwide [3]. The ten recommendations of the WHO include:

Commit to a healthy recovery: Commit to a healthy, green, and just recovery from COVID-19 and other respiratory and cardio-vascular diseases due to air pollution.

Placing health and social justice must be at the heart of the UN and country's climate talks.

Prioritise actions: Prioritize climate interventions with the largest health and socio-economic gains.

Build health resilience to climate risks. Build climate resilient and environmentally sustainable health systems and facilities, and support health adaptation and resilience across sectors.

Create Climate friendly energy systems, all nations to commit to deliver a rapid and just transition away from fossil fuels, starting with immediately cutting all related permits, subsidies, and financing for fossil fuels, and to completely shift current financing into development of clean energy and end energy poverty in homes / health facilities.

Health Systems Reformation: call on governments to build climate resilient, low-carbon, sustainable health systems.

Reimagine urban environments, transport, and mobility: Promote sustainable, healthy urban design and transport systems, with improved land-use, access to green and blue public space, and priority for walking, cycling and public transport.

Protect and restore nature: Protect and restore natural systems, the foundations for healthy lives, sustainable food systems and livelihoods.

Promote healthy, food systems. Promote sustainable and resilient food production, that are more affordable, nutritious diets that deliver on both climate and health outcomes.
Finance greener future to save lives. Transition towards a wellbeing economy and high-income countries to also provide the promised transfer of funds to low-income countries to help achieve the necessary mitigation and adaptation measures.

Covid 19 Pandemic Recovery action: Ensure that pandemic recovery investments world-wide support climate action and reduce social and health inequities.

Community Mobilization: Listen to the health community, mobilize, and support the health community actions on climate.

\section{Indian commitments}

India's ambitious 450 GW renewable energy goal by 2030, its hydrogen mission, plan to move Indian railways to 'net-zero' emission by 2030 , land degradation neutrality and massive programme to increase forest cover- natural carbon sink would be the key points the country will commit to drive home at $\mathrm{COP} 26$. It is expected that the PM would urge all countries to participate in three key multilateral institutions/efforts, namely i) International Solar Alliance (ISA), ii) Coalition for Disaster Resilient Infrastructure (CDRI) and iii) Leadership Group for Industry Transition (LeadIT) - to strengthen mitigation and adaptation goals of the Paris Agreement [4,5]. India would also launch Green Grid Initiative (GGI) of trans-national solar grid through ISA, India, UK, and Australia and launch, Infrastructure for Resilient Island States (IRIS) - through CDRI to support small island nations.

India is aggressively promoting battery cars and plugin cars just like any other electrical device. Tesla is the most famous plug-in, but Tata and Mahindra also make them assure Atma-nirbhar Bharat. China and Europe together bought more than 2 million plug-in cars between January and June this year. Toyota just coaxed one of its Mirai fuel cell cars into travelling $1,352 \mathrm{~km}$ on $5.7 \mathrm{~kg}$ of hydrogen. Hydrogen packs 2.6 times more energy per kilogram than natural gas. A few kilos of hydrogen pack provide more energy than a large battery. Hydrogen is not the best fuel for running cars at present, but it has an advantage over plug-in vehicles in heavy applications. Running a heavy container truck, railway diesel engines, construction machinery, Ships, and planes on hydrogen, may be economically viable soon. Hydrogen appears to be the fuel of choice in future [6].

As highlighted by IPCC the world must achieve net zero by 2050. For this India must address following five-point actions for climate change Challenge.

1. Enabling policies to reduce green hydrogen costs: Power costs including generation and transmission contribute to more than $70 \%$ of green hydrogen cost. As it is cheaper to transport electricity than hydrogen, initiatives such as transmission and distribution waivers, surcharge waivers and low taxes/duties will help reduce green hydrogen costs by enabling the electrolysis facilities to be set up closer to demand centres.

2. Reducing prices of green hydrogen: India is estimated to consume 11.7 million tons of carbon-intensive industrial grey hydrogen by 2030, primarily in the 
refinery and fertiliser sector, twofold of the 5.6 MTs today. India must ensure that a large proportion of the upcoming new hydrogen capacity should be green in addition to mandating a fraction of existing capacities to go green. Long distance transport sector can also provide additional demand in the form of hydrogenderived ethanol or hydrogen fuel cells. India is targeting 5 million tons of zero-carbon hydrogen production by 2030 serving both existing and new applications. This should radically bring down the price of hydrogen from the present $\$ 4$ per $\mathrm{kg}$ to $\$ 1$ by 2030. Methane can be an alternatvei fuel due to hihg potential of growing Sugar Cane in India.

3. Preparing sunrise sectors: like green steel for green hydrogen is critical for creating vibrant clean export capabilities in India. This is one of the few countries whose steel demand is growing rapidly, it is set to triple its steel production by 2030. This is an excellent opportunity for the Indian steel industry to create the world's largest green steel capacity. It is estimated that with government support and ambitious private initiatives, around 15 MTs of high-margin exportoriented green steel capacity can be created in India by 2030.

4. Manufacturing and innovation capabilities: They are critical to achieve true Atmanirbharta in the green hydrogen industry. To address the low supply of electrolysers in the world, India is building capacities to produce $20 \mathrm{GW}$ of long-lasting electrolysers in the coming decade. R\&D investments become critical to the success of the Indian electrolyser industry, where the roles of venture capital and academia-industry partnerships are imperative.

5. Decarbonisation: Decarbonization is a global agenda and India can also enable the net-zero ambitions of our East Asian allies. Scaled-up green ammonia synthesis in the Indian coast can be a historical opportunity to export energy. A well-designed alliance with Korea, Singapore, Taiwan, and Japan will enable win-win partnerships.
With proactive collaboration between innovators, entrepreneurs and government, green hydrogen has the potential to drastically reduce $\mathrm{CO}_{2}$ emissions, fight climate change, and put India on a path towards net-zero energy imports. It will also help India export high-value green products making it one of the first major economies to industrialise without the need to 'carbonise' [7].

The key outcomes of the summit were:

1.The Global action agenda for innovation in Agriculture

2. Supporting the conditions for a just Transition

3. Focus of Energy Transition Council

4. Global Coal to Clean Power Transition

5. Mission Innovation breakthrough Energy Collaboration

6. Green Grids Imitative- 'One Sun, One World-One Grid'

India is among the backers of the coalition on deforestation commitments as its framework has trade linkages that are not in the country's interests. Similarly, the plans to reduce methane would impact our farm sector as the gas also comes from paddy cultivation and livestock.

\section{References}

1. UNICEF Children's climate index report 2021

2. Climate emergency Perceptions 2021

3. WHO's 10 calls for climate action to assure sustained recovery from COVID-19. Link: https://bit.ly/3CWHbF8

4. Bhushan C (2021) COP26: Realistic Expectations. COP26: Realistic expectations - Glasgow will not solve the climate crisis but it can fast-track global climate collaboration. Link: https://bit.ly/3087vht

5. India finalises strategy for next week's leaders' summit, COP26.

6. Hydrogen now has a real chance to be petrol of the future 2021

7. Kant A (2021) India's Clean Molecule Bet. Link: https://bit.ly/3CZHQWs
Discover a bigger Impact and Visibility of your article publication with

Peertechz Publications

\section{Highlights}

* Signatory publisher of ORCID

* Signatory Publisher of DORA (San Francisco Declaration on Research Assessment)

- Articles archived in worlds' renowned service providers such as Portico, CNKI, AGRIS, TDNet, Base (Bielefeld University Library), CrossRef, Scilit, J-Gate etc.

* Journals indexed in ICMJE, SHERPA/ROMEO, Google Scholar etc.

* OAI-PMH (Open Archives Initiative Protocol for Metadata Harvesting)

* Dedicated Editorial Board for every journal

- Accurate and rapid peer-review process

* Increased citations of published articles through promotions

* Reduced timeline for article publication

Submit your articles and experience a new surge in publication services (https://www.peertechz.com/submission). 